\title{
ALGUNAS DISCREPANCIAS CON ERNESTO GARZÓN EN MATERIA DE DERECHOS HUMANOS
}

\author{
Jesús González Amuchastegui \\ Universidad Complutense de Madrid
}

RESUMEN. El texto recoge la respuesta del autor del libro citado a las tres observaciones que Ernesto Garzón realizó en el prólogo del mismo. Las discrepancias giran en torno a la historicidad de las concepciones de los derechos humanos defendida por el autor y cuestionada por el prologuista; al modelo de organización internacional exigido por las teorías de los derechos humanos: una asociación de Estados democráticos o una institución internacional democrática e «intervencionista» en materia de derechos humanos; y a la relevancia moral del principio de dignidad humana que el autor circunscribe a fundamentar los derechos de la personalidad y de seguridad, mientras Garzón lo amplia a fundamentar una regulación jurídica moralmente aceptable.

Palabras clave: Ernesto Garzón Valdés, derechos humanos, dignidad.

ABSTRACT. This text constitutes the answer of the author of the above quoted book to three comments about it formulated by Ernesto Garzón in its prologue. These comments referred to disagreements about the historicity of the human rights theories proposed by the author and criticised by Garzon; the pattern of international organization required by these human rights theories: an association of democratic States versus a democratic international institution which is «interventionist» in the field of human rights; and the moral relevance of the principle of human dignity which the author bases on identity and «rule of law» rights, while Garzon considers it to be more generally the basement of a morally acceptable legal order.

Keywords: Ernesto Garzón Valdés, human rights, dignity. 
1 texto que voy a comentar constituye el prólogo que Ernesto GARZÓN realizó en 2004 a una obra que pretendía, según su autor, «mostrar que el Estado Social y Democrático de Derecho es el único modo de organización social y político compatible con la concepción de los derechos humanos que defenderé», y para lo cual, a lo largo de dicho libro analiza las características de las teorías de la justicia basadas en la idea de derechos humanos, define los rasgos básicos de ese tipo especial de derechos que llamamos «derechos humanos» y pretende justificar cuáles son éstos.

GARZÓN VALDÉS destina el prólogo a analizar críticamente tres cuestiones abordadas en el mencionado libro: la versión historicista de los derechos humanos, la posible organización de un orden internacional justo y la relevancia moral del principio de dignidad humana. Veamos sus consideraciones:

\section{LA VERSIÓN HISTORICISTA DE LOS DERECHOS HUMANOS}

GARZÓN cuestiona la tesis historicista defendida en el libro, según la cual las teorías de los derechos humanos - exactamente igual que todas las restantes teorías de la justicia que en el mundo han existido- son una «invención» humana, invención que se produjo en un momento determinado de la historia europea, en el tránsito a la modernidad. En opinión de GARZÓN, «esta conclusión no sólo es moralmente desconcertante, sino empíricamente falsa».

Aduce en favor de su tesis varios ejemplos, desde EsQuiLO a MONTAIGNE, que mostrarían no sólo que los derechos humanos serían intemporales, sino también que pueblos anteriores y ajenos al antes citado tránsito europeo a la modernidad podrían ser moralmente superiores a los europeos.

Su argumento más fuerte contra la historicidad de los derechos humanos es, sin embargo, de otro orden: «si los titulares de los derechos humanos son las personas, si ellos les pertenecen por el hecho de ser tales, aceptar la tesis de la "invención" significaría o bien que hasta su invención los seres humanos no eran personas o si lo eran entonces no es verdad que valgan sin más para todas las personas, ya que sólo valdrían para quienes han tomado conocimiento de esta invención».

Finaliza su argumentación proponiendo distinguir entre «descubrir, inventar y nombrar», enfatizando que «nombrar no es ni descubrir ni inventar», y concluyendo que «es verdad que la expresión "derechos humanos" es relativamente reciente y ha sido incorporada al lenguaje de la moral en un momento determinado, pero de aquí no se infiere que lo nombrado no existiera ya antes».

Es verdad que si bien parece cierto que, como cantaron Bob Dylan, y Javier Krahe y Sabina entre nosotros, «el hombre puso nombre a los animales», y no por ello éstos carecían de existencia antes de su «bautismo»; y aunque también es verdad que, como el burgués de Molière que hablaba en prosa sin saberlo, es posible hallar, por ejemplo, líderes políticos comprometidos con la defensa de los derechos humanos sin conocer esta noción, me parece que si concebimos los derechos humanos como una concepción de la justicia que intenta ofrecer una respuesta a los principales interrogantes que plan- 
tea la convivencia humana en sociedad, no podemos atribuir a este tipo de teorías -las basadas en derechos humanos-el rasgo de la intemporalidad.

No me cabe duda de que la noción de dignidad como atributo característico de los seres humanos que impide que éstos sufran determinado tipo de tratamientos, ha estado presente desde los albores de la humanidad (aunque es dudoso que el círculo de los seres humanos que disfrutaba de tal dignidad abarcara a negros, mujeres, esclavos, discapacitados...), pero no estoy seguro, repito, de que ello implique proclamar la intemporalidad de las teorías de la justicia basadas en derechos humanos. Además, aunque no me niego a admitir que haya habido comunidades superiores moralmente a las europeas, he de confesar que me cuesta mucho aceptar que haya o haya habido concepciones de la justicia más sólidamente justificadas que las teorías de los derechos humanos.

\section{POSIBLE ORGANIZACIÓN DE UN ORDEN INTERNACIONAL JUSTO}

Las tesis cosmopolitas del profesor GARZÓN, sostenidas en diferentes publicaciones que no hace falta recordar, y presentes en el libro que prologa, le llevan a defender como máximo ideal alcanzable, frente a las tesis más ambiciosas del autor del libro, «la libre asociación de Estados democráticos [...] para ir acercándose así a una sociedad universal más justa».

Su argumentación es la siguiente: a partir de la noción de «coto vedado», noción básica en su diseño democrático-representativo, se plantea si dicho coto (entendido ahora como derechos humanos más principio de no intervención) existe también respecto de las normas que rigen (o deberían regir) las relaciones entre Estados. Su conclusión es negativa por tres razones: en primer lugar, por las diferencias existentes entre persona individual y Estado soberano, que cuestionan la equiparación entre las nociones de soberanía y legitimidad; en segundo lugar, por la extraordinaria diferencia existente entre la aplicación de sanciones a nivel nacional y a nivel internacional (en este último ámbito las sanciones tienen un carácter tan difuso que, como mínimo, conducen a castigar a inocentes); y por último, por la inexistencia en el orden jurídico internacional de un Estado único mundial que posea legitimidad democrática para imponer su regulación jurídica en dicho ámbito.

Por ello, como apuntaba anteriormente, y aunque proclama que «en el ámbito de la política, tanto a nivel nacional como internacional, la existencia de un "coto vedado" seriamente respetado es la única garantía contra el despotismo y la indecencia», no cree que en aras de asegurar la vigencia del «coto vedado» se pueda ir más allá de procurar la libre asociación de Estados democráticos.

Dos dudas surgen en relación con las consideraciones de GARZÓN: la primera, ¿por qué el principio de no intervención forma parte del coto vedado en el marco internacional? Si asumimos con GARZÓN que los derechos humanos que integran el coto vedado no sólo persiguen en el marco estatal definir un ámbito despolitizado que garantice el ejercicio de la autonomía personal, sino que también son fuente de exigencias de normación positiva pues requieren la intervención política a fin de lograr su vigencia efectiva, no veo especial dificultad en defender que, en el marco de las relaciones inter- 
nacionales, y toda vez que muchos Estados no garantizan ese coto vedado, los derechos humanos son también fuente de exigencias de normación positiva internacional, que si chocan con el principio de soberanía estatal, pueden vencerlo, pues, como el propio GARZÓN muestra, la analogía entre persona individual y Estado soberano, y la consiguiente atribución de calidad moral a éste, no son aceptables.

La segunda observación destacaría el carácter pesimista de la propuesta de GARZÓN. ¿No cabría intentar algo más que la mera asociación libre de Estados democráticos?, ¿no merecería la pena procurar una institucionalización internacional más potente, democrática y comprometida con la defensa de los derechos humanos? Quiero pensar que la respuesta afirmativa a ambos interrogantes es algo más que un exceso de la voluntad o que un mal sueño de la razón.

\section{LA RELEVANCIA MORAL DEL PRINCIPIO DE DIGNIDAD HUMANA}

Asumiendo en sus consideraciones sobre el principio de dignidad una orientación kantiana, GARZÓN concluye dicha reflexión señalando que dicho principio «fija el umbral mínimo a partir del cual pueden diseñarse diversas regulaciones para la adjudicación y/o distribución de bienes en una sociedad», o lo que es lo mismo, que su relevancia moral radica en la «determinación del contenido y alcance no sólo de los derechos humanos, sino de una regulación jurídica moralmente justificable».

No estoy seguro de compartir plenamente el planteamiento de GARZÓN, pues si bien es verdad que podemos justificadamente incluir bajo el paraguas de la dignidad humana todas las exigencias de justicia (y, por tanto, todos los derechos humanos), o, con palabras de GARZÓN, sostener que «los derechos humanos o fundamentales (civiles, políticos, sociales) forman parte esencial de un diseño adecuado para lograr la concreción de las exigencias del respeto a la dignidad humana», me inclino por buscar en este principio, concebido también a la manera kantiana, el fundamento de un grupo especial de derechos, de dos realmente, por un lado, los derechos de la personalidad (que pretenden garantizar nuestra individualidad y nuestro status de sujetos titulares de derechos humanos) y, por otro, los de seguridad, que incluyen las garantías procesales y humanitarias en materia penal. 